\title{
Potentiometric Multisensory Systems with Novel Ion-Exchange Polymer-Based Sensors for Analysis of Drugs
}

\author{
Olga V. Bobreshova, Anna V. Parshina, and Ksenia A. Polumestnaya \\ Department of Analytical Chemistry, The Voronezh State University, Universitetskaya pl. 1, Voronezh 394006, Russia \\ Correspondence should be addressed to Olga V. Bobreshova, polumestny@mail.ru
}

Received 20 June 2011; Accepted 7 September 2011

Academic Editor: Karl Scott Ryder

Copyright ( $) 2012$ Olga V. Bobreshova et al. This is an open access article distributed under the Creative Commons Attribution License, which permits unrestricted use, distribution, and reproduction in any medium, provided the original work is properly cited.

\begin{abstract}
This paper examines potentiometric multisensory systems that consist of novel cross-sensitive PD-sensors (Potential Donnansensors). The analytical signal of PD-sensors is the Donnan potential at the ion-exchange polymer/electrolyte test solution interface. The use of novel sensors for the quantitative analysis of multicomponent aqueous solutions of amino acids, vitamins and medical substances is based on protolytic and ion-exchange reactions at the interfaces of ion-exchangers and test solutions. The potentiometric sensor arrays consist of PD-sensors and ion-selective electrodes. Such systems were developed for the multicomponent quantitative analysis of lysine monohydrochloride, thiamine chloride and novocaine hydrochloride solutions that contained salts of alkaline and alkaline-earth metals, as well as for mixed solutions of nicotinic acid and pyridoxine hydrochloride. Multivariate methods of analysis were used for sensor calibration and the analysis of the total response of sensor arrays. The errors of measurement of the electrolytes in aqueous solutions did not exceed $10 \%$. The developed multisensory systems were used to determine the composition of a therapeutic "Mineral salt with low content of sodium chloride" and to determine concentrations of novocaine in sewage samples from a dental clinic.
\end{abstract}

\section{Introduction}

UV spectrophotometry [1], spectrofluorimetry [2], and HPLC [3] are commonly used methods for the quantitative analysis of amino acids, vitamins, and medical substances in aqueous solutions.

The advantages of potentiometric methods include the possibility of rapid, in situ analysis, the automation and separation of measurements, the simplicity of the technique, and the absence of any probe preparation [4-6]. The direct potentiometric determination of ions in aqueous solutions is based on either the measurement of membrane potential or oxidation-reduction potential of ion-selective electrodes (ISEs). Classical representations of ISEs are based on the theory of a glass electrode [7-10]. The Nicolsky-Eisenman equation can be applied to the description of a sensor response in multicomponent solutions. The influences of interfering ions are considered by means of selectivity constants, which are strictly reasonable only for binary systems. The use of ISEs in real systems is currently limited by their low selectivity and accuracy in multicomponent systems.

Modern investigations in the field of potentiometric sensors have taken the following approaches: the search for novel materials useful for the construction of ISEs [11-13], the miniaturisation of sensors $[14,15]$, the elimination of a transmembranous stream of defined ions from an ISE internal reference solution in test solutions [16, 17], the development of a theory describing ISEs without restrictions concerning equilibrium or steady state $[6,18]$ and research and development of multisensitive systems for the analysis of multicomponent liquid environments [19-25].

A multisensitive system includes an array of cross-sensitive sensors (i.e., sensors that are sensitive to several components in a given solution) and algorithms for processing the multidimensional data from a sensor array [19-26]. References [21-25] offer criteria for an estimation of crosssensitivity, including the average inclination (i.e., sensitivity factor), the stability factor, and the nonselectivity factor. 
The sensitivity factor $S=(1 / n) \sum S_{i}$ is the average value of lean angles from calibrations $S_{i}$ of all sensors in an array in individual solutions of defined components. The stability factor $K=(1 / n) \sum\left(S_{i} / D_{i}\right)$ is the average value of a lean angle $S_{i}$ relative to the distribution of lean angles $D_{i}$ from calibrations of all sensors in individual solutions of defined components. The nonselectivity factor $F=S / D$ is the average inclination $S$ relative to a distribution $D$ of the average inclinations. The response of an array of cross-sensitive sensors is difficult because it contains information from various components that are present in the test solution, in addition to their interactions. Multivariate calibrations reduce the uncertainty of the analysis and reveal internal hidden interactions between variables as a result of increasing concentrations [27]. Established potentiometric multisensitive systems, such as the "electronic tongue," only permit qualitative and semiquantitative analyses of foodstuffs and pharmaceutical products [19-26].

Recently, we described the development of a novel potentiometric sensor (PD sensor), which measures the Donnan potential at an ion-exchange polymer (IEP)/electrolyte test solution interface [28-33]. The Donnan potential is the Galvani potential between two points outside the external interfaces of double electrical layers (DELs) at the IEP/test solution interface [34-37]. Consequently, it is impossible to directly measure the Donnan potential; however, it is possible to estimate its value. An attempt to define the Donnan potential is known. For this purpose, the electromotive force (EMF) of the electrochemical circuit is measured, which includes two reference cells with reference electrodes, two reference solutions, and two salt bridges. One salt bridge is in contact with a test solution of the inorganic salt, and the second is in contact with a membrane surface. Additionally, the membrane is also in contact with a test solution [38]. One disadvantage of this method includes the short time of potential stability $(1.5-2.0 \mathrm{~min})$ due to transmembranous transport. Similarly, we determine the Donnan potential by measuring the EMF of the electrochemical circuit, but it is measured from the potential jump at the individual ionexchanger/test solution interface [28-31]. The use of the membrane potential equilibrium constant as an analytical signal, which is the Donnan potential at the IEP/test solution interface, allows us to eliminate issues related to migration and diffusion in ionophore-based potentiometric sensors $[16,17]$. This process ultimately increases the accuracy, stability and sensitivity of organic and inorganic ion measurements.

We have previously described the application of the PD sensor for the selective determination of lysine in the presence of neutral amino acids, ammonium ions [28, 32], and PD sensors, which are cross-sensitive in multicomponent solutions of some amino acids, vitamins, medicinal substances, and inorganic salts $[29,30,33]$.

The aim of this paper was to develop potentiometric multisensory systems with novel polymer-based ion-exchange PD sensors for the determination of inorganic ions and various ionic forms of organic electrolytes in multicomponent aqueous solutions. Specifically, the analytes of interest were amino acids, vitamins, and medical substances.

\section{Experimental}

2.1. Reagents. All chemicals were of analytical reagent grade. All solutions were prepared using distilled water with a resistance of $0.35 \mathrm{M} \Omega \cdot \mathrm{cm}$. The following analytes of interest were dissolved in aqueous solutions: lysine monohydrochloride (LysHCl), thiamine chloride (ThiaminCl), pyridoxine hydrochloride (PyridoxinHCl), nicotinic acid (Niacin), novocaine chloride (NovHCl), and inorganic electrolytes $(\mathrm{NaCl}$, $\mathrm{KCl}, \mathrm{CaCl}_{2}$, and $\mathrm{MgSO}_{4}$ ). Concentrations of the various solution components ranged from $1.0 \times 10^{-4}$ to $1.0 \mathrm{M}$. The $\mathrm{pH}$ values of $\mathrm{LysHCl}+\mathrm{KCl}+\mathrm{NaCl}+\mathrm{MgSO}_{4}$, ThiaminCl + $\mathrm{KCl}+\mathrm{NaCl}$, NovHCl $+\mathrm{KCl}+\mathrm{NaCl}$, and PyridoxinHCl + Niacin solutions were $5.27 \pm 0.05,(3.46-4.65) \pm 0.04,4.5 \pm$ 0.4 , and $(3.12-4.40) \pm 0.05$, respectively.

Systems containing sulphocation-exchange polymers with different structures (i.e., homogeneous perfluorinated sulphocation-exchange MF-4SK membranes and tubes, which are Russian analogues of Nafionc, and heterogeneous hydrocarbonic MC-40 membranes) and individual solutions of inorganic electrolytes (i.e., $\mathrm{HCl}, \mathrm{NaCl}$, and $\mathrm{KCl}$ ) were previously researched for the selection of ion-exchange materials.

The structure of perfluorinated sulphocation-exchange polymers (PSPs) is formed from a system of nanopipes (10$17 / 5-10 / 3-5 \mathrm{~nm})$ and pores $(0.75-1.25 \mathrm{~nm})$ with hydrophobic walls and hydrophilic sulphonate ionic groups within the channel volumes. The structural units of the hydrocarbonic polymers are represented by macroclusters of micropores with radii of $2-3 \mathrm{~nm}$. The structural units of the hydrocarbonic polymers include ion-exchange groups and hydrophilic regions in a matrix that is divided by meso- and macropores with $5 \div 500 \mathrm{~nm}$ radii. The meso- and macropores are filled with test solution and include polymeric chains and an inert material [39].

PSPs are characterised by optimal selective properties as a result of fewer numbers of mesopores and the complete absence of macropores. Thus, the presence of hydrophobic (i.e., polytetrafluoroethylene chains) and hydrophilic (i.e., sulphonate ionic groups) regions in such polymers provides the matrix with labile structural components, which allows for the electrochemical properties of PSPs to be controlled by changing the ionic form of the polymers. Therefore, the hydrophobicity of the matrix from PSP and the absence of macropores together define a greater interface transition activation energy of hydrated ions compared to heterogeneous hydrocarbonic polymers. Hence, the use of PSPs in PD sensors provides increased signal, sensitivity, and accuracy in comparison with hydrocarbonic polymers. The comparison of the sensitivity of PSP-based PD sensors and MK-40 membranes for a number of inorganic ions is shown in Figure 1.

2.2. Apparatus. All solutions were analysed at $25 \pm 0.05^{\circ} \mathrm{C}$ using a liquid thermostat TJ-TS-01/12. All potentiometric measurements were performed using an Expert-001-3(0.1) fluid analyser. The reported relative error for this device for $\mathrm{pH}$ and EMF measurements is $2.5 \%$ and $1.5 \%$, respectively. A potassium-selective electrode (K-SE, ELIS-121 K), 


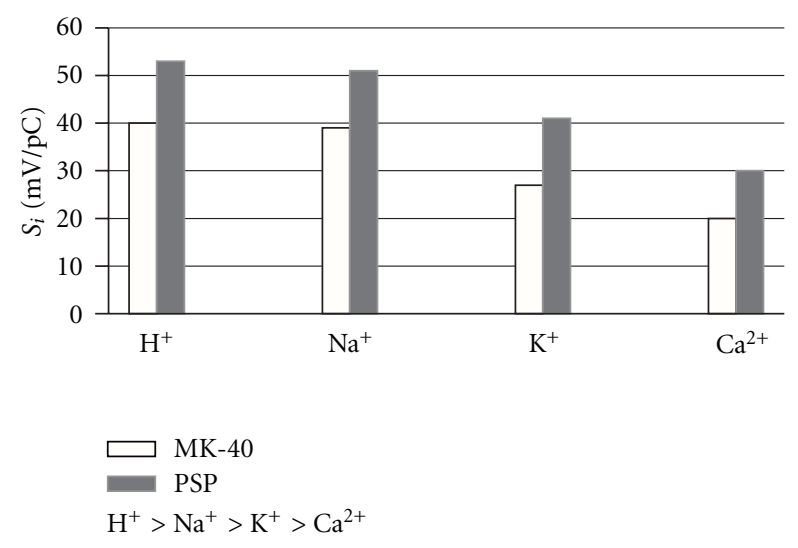

FIgURe 1: Sensitivity of PD sensors based on PSP and MC-40 in corresponded ionic types in test solutions of $\mathrm{HCl}, \mathrm{NaCl}, \mathrm{KCl}$, and $\mathrm{CaCl}_{2}$.

calcium-selective electrode $(\mathrm{Mg}(\mathrm{Ca})-\mathrm{SE}$, ELIS-121Mg(Ca)) with a polyvinylchloride membrane, glass sodium-selective electrode (Na-SE, ELIS-112Na), silver chloride/silver reference electrode (EVS-1M3.1), and glass electrode (ELS-4307) were all used for the $\mathrm{pH}$ control of test solutions. The sensors were rinsed with distilled water for $30 \mathrm{~s}$ between measurements.

\subsection{Organisation Principles of Potentiometric Multisensory} Systems with PD Sensors. A scheme of an electrochemical cell for analysing multicomponent aqueous solutions of organic and inorganic electrolytes [29-31] is presented in Figure 2.

The sensor array included PD sensors $\left(\mathrm{A}_{i}\right), \operatorname{ISE}\left(\mathrm{B}_{i}\right)$, and a silver chloride/silver reference electrode $(C)$. The potentials of sensors $\mathrm{A}_{i}$ and $\mathrm{B}_{i}$ were measured with reference electrode $\mathrm{C}$ using a high-resistance electronic voltmeter $\mathrm{V}$. Responses from electrode $A_{i}$ registered after 5-7 min, which was the time it took to reach a quasiequilibrium state [29-31].

The PD sensor [28] included two plastic encasements, designated 1 and 2, with volumes of 5 and $0.5 \mathrm{~cm}^{3}$, respectively. Encasements 1 and 2 were connected to a rubber stopper 3. Encasement 1 was filled with reference solution. Depending on the ionic form of the polymer, $1 \mathrm{~mol} / \mathrm{l} \mathrm{solu-}$ tions of $\mathrm{HCl}$ or $\mathrm{KCl}$ were used as reference solutions. Encasement 2 prevented the IEP from drying. The internal reference electrode 4, which was a silver wire covered with $\mathrm{AgCl}$, was fixed in encasement 1 and immersed in a $1 \mathrm{M} \mathrm{KCl}$ solution. The free end of the $6-8 \mathrm{~cm}$ long PSP (both tube and membrane) 5 was fixed in stoppers 3 and 6 and was immersed in the test solution.

The electrochemical circuit (1) for the determination of the response of the PD sensor was constructed in the following configuration [29-31]:

$\mathrm{Ag} \mid \mathrm{AgCl}, 1 \mathrm{M} \mathrm{Cl}^{-}$| PSP | test solution | sat. $\mathrm{KCl}, \mathrm{AgCl} \mid \mathrm{Ag}$,

$$
\begin{aligned}
E= & \Delta \varphi_{\mathrm{Ag} / \mathrm{AgCl}}^{0(\mathrm{~A} / \mathrm{C})}+\Delta \varphi_{\mathrm{PSP}}^{1 \mathrm{MCl}^{-}}+\Delta \varphi_{\text {diff }}+\Delta \varphi_{\text {test-solution }}^{\mathrm{PSP}} \\
& +\Delta \varphi_{\text {sat.KCl }}^{\text {test-solution }}-\Delta \varphi_{\mathrm{Ag} / \mathrm{AgCl}}^{0(\mathrm{C})}
\end{aligned}
$$

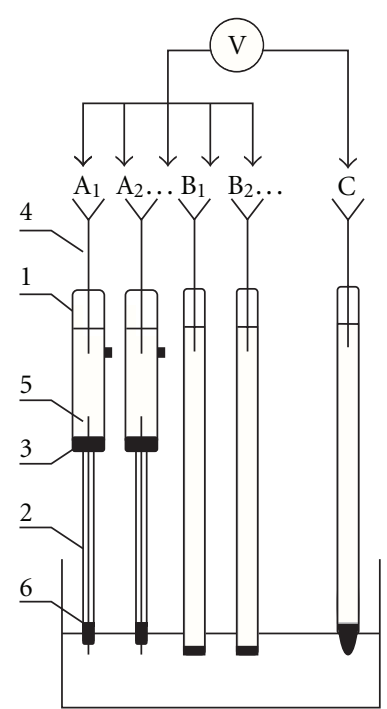

Figure 2: The scheme of the electrochemical cell for the determination of organic electrolytes in multicomponent test solutions: $\mathrm{A}_{i}$ is the PD sensor; 1, 2 are plastic encasements; 3,6 are rubber stoppers; 4 is internal reference electrode; 5 is PSP in $\mathrm{K}^{+}$-type; 7 is $1 \mathrm{M} \mathrm{KCl} ; 8$ is the test solution; $\mathrm{B}_{i}$ is ISE; $\mathrm{C}$ is silver chloride/silver electrode; $\mathrm{V}$ is high-resistance voltmeter.

where $\Delta \varphi_{\mathrm{Ag} / \mathrm{AgCl}}^{0(\mathrm{~A} / \mathrm{C})}$ and $\Delta \varphi_{\mathrm{Ag} / \mathrm{AgCl}}^{0(\mathrm{C})}$ are the standard potentials of an intrinsic reference electrode of the PD sensor (A) and reference electrode $(\mathrm{C})$, respectively; $\Delta \varphi_{\mathrm{PSP}}^{1 \mathrm{MCl}^{-}}$is the potential difference at the interface between the intrinsic reference solution of the PD sensor (A) and PSP; $\Delta \varphi_{\text {diff }}$ is the diffusion potential in the PSP phase; $\Delta \varphi_{\text {test-solution }}^{\mathrm{PSP}}$ is the Donnan potential at the interface PSP/test solution; $\Delta \varphi_{\text {sat.KCl }}^{\text {test-solution }}$ is the potential difference at the test solution/ $\mathrm{KCl}$ saturated solution interface of the reference electrode (C).

The organisation of the PD sensor is as follows. The sum of all potential jumps in the EMF (1) was negligibly small compared to the Donnan potential at the PSP/test solution interface. The concentration of the reference solution was comparable to the concentration of fixed groups in PSP. The interfaces of the PSP/test solution and PSP/reference solution in the PD sensor were separated, which allowed us to neglect the influence of diffusion and migration processes on the analytical signal. Thus, the analytical signal of the PD sensor was the Donnan potential at the PSP/test solution interface. The quantitative consideration of the contributions of potential jumps at all interfaces to the total EMF for determination of the response of the PD sensor was presented previously [30].

2.4. Multivariate Calibration Methods. The stability, sensitivity, and selectivity of sensors were estimated in individual solutions of analytes. The determination of activity coefficients in the polyionic systems is a difficult scientific problem. Therefore, calibration of the sensors was performed in the $\Delta \varphi_{D} / \mathrm{pC}$ coordinates. In this case, information about the relationship between activity and ion concentration in 


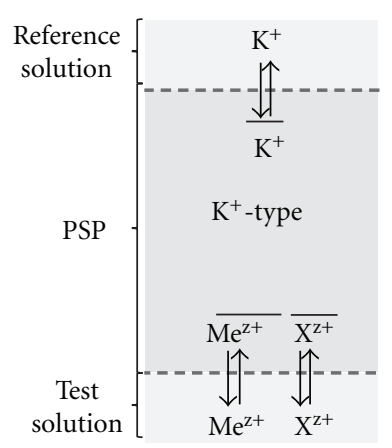

(a)

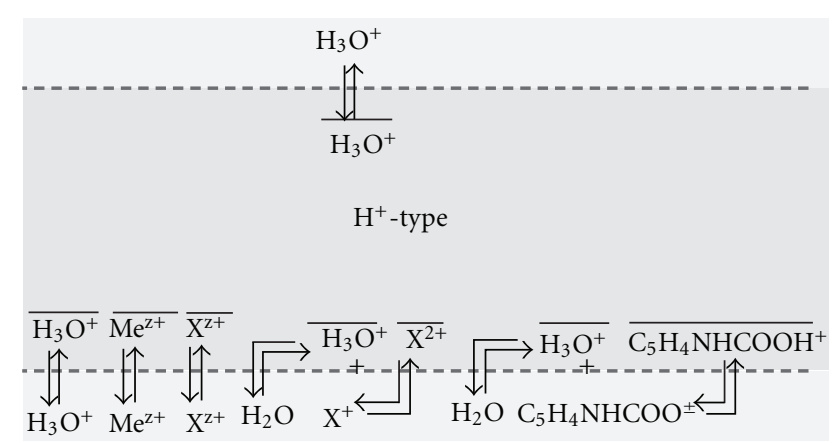

(b)

FIgure 3: The quasiequilibria at the interface of PSP in K-type (a) and $\mathrm{H}^{+}$-type (b) with test and reference solutions in PD sensor: $\mathrm{X}^{+}$is lysine, thiamin, and novocaine cations, $\mathrm{Me}^{\mathrm{z}+}$ is cations of alkaline, and alkaline-earth metals.

the phase of a solution and in the phase of the PSP was contained in the calibration coefficients.

Multivariate calibration methods were used to deduce the calibration equations for the calculation of analyte concentrations in mixed test solutions. The values of factors of concentrations were changed with a constant step. Initial factors were encrypted so that the sum of the values of any two factors from all experiments was equal to zero, which satisfied the requirements of nondegeneracy and orthogonality for the experimental plan. The absence of systematic errors and insignificant distinction of variances was a necessary requirement for the responses of sensors. Statistical models that did not take into account (3) and that did take into account (4), the interference of different components, were utilised to calculate concentrations of components and were as follows:

$$
\begin{gathered}
E_{k}=\mathrm{B}_{0}+\sum_{i=1}^{3} \mathrm{~B}_{i} \cdot \mathrm{pC}_{i}, \\
E_{k}=\mathrm{B}_{0}+\sum_{i=1}^{3} \mathrm{~B}_{i} \cdot \mathrm{pC}_{i}+\sum_{i=1}^{3} b_{i j} \cdot \mathrm{pC}_{i} \cdot \mathrm{pC}_{j},
\end{gathered}
$$

where $E_{i}$ is the response of $i$-sensor, $\mathrm{mV} ; b_{0}, b_{i}$, and $b_{i j}$ are coefficients of calibration equations, $\mathrm{mV} / \mathrm{pC} ; \mathrm{pC}_{i}$ and $\mathrm{pC}_{j}$ are the negative decimal logarithm of concentrations of investigated $i, j$-components.

The coefficients of multivariate calibration equations were determined by the method of least squares [27]. The values of the calibration coefficients were compared to the fitting errors to verify their statistical significance. To verify the adequacy of the calibration equations, the difference between the calculated and experimental response values of the sensors was compared to the distribution results from the duplicated experiments. A spreadsheet was used to calculate regression parameters for the sensor calibration curves.

\section{Results and Discussion}

The PD sensors were organised so that quasi-equilibria, which are formed at PSP/test solution and PSP/reference solution interfaces, are stable as a function of time and are independent from each other. The ionic properties and concentrations in the solution phase volumes and the ionexchanger were slightly changed [34], permitting the use of PSP in the PD sensors, which were not transferred into the electrolyte test solution. Both inorganic ions of the initial form of an ion-exchanger and various ionic forms of organic electrolytes take part in the formation of the Donnan potential at the IEP/test multicomponent solution interface.

In systems with inorganic electrolytes, ion-exchange reactions are potentially defining. In such reactions, a hydrated shell of ions partially breaks up in solution phase and then reorganises in the PSP phase. Therefore, the sensitivity of the PD sensor to solution phase inorganic ion concentrations increases with decreasing charge, crystallographic radius, and increase in degree of hydration (Figure 1).

Various functional groups $\left(-\mathrm{NH}_{2},-\mathrm{COOH}\right)$ are present in the structure of amino acids, vitamins, and medical substances. These functional groups are capable of participating in ion-exchange and proteolytic reactions in the solution phase, PSP, and at the interface. The quasi-equilibria at the $\mathrm{PSP} /$ multicomponent test solution interface for $\mathrm{K}^{+}$- and $\mathrm{H}^{+}$type PSPs are shown in Figures 3(a) and 3(b), respectively.

The potential defining reactions of PSP-based $\mathrm{K}^{+}$-type $\mathrm{PD}$ sensors are ion-exchange reactions. The PSP-based $\mathrm{K}^{+}$type $\mathrm{PD}$ sensor was characterised by high sensitivity to all organic $(41 \pm 2 \mathrm{mV} / \mathrm{pLysH}, 38 \pm 4 \mathrm{mV} / \mathrm{p}$ ThiaminH, $51 \pm$ $4 \mathrm{mV} / \mathrm{pNovH}$, and $36 \pm 2 \mathrm{mV} / \mathrm{pPyridoxinH}$ ) and inorganic $(44 \pm 2 \mathrm{mV} / \mathrm{pNa}, 42 \pm 2 \mathrm{mV} / \mathrm{pK}$, and $32 \pm 2 \mathrm{mV} / \mathrm{pMg})$ ions (Figure 4). Thus, these ion-exchange reactions were the cause of cross-sensitivity of PD sensors in the multicomponent test solutions, in addition to solutions of ThiaminCl and $\mathrm{NovHCl}$ (i.e., the sorption of $\mathrm{Thiamin}^{+}$and $\mathrm{NovH}^{+}$ions was difficult because of their size). The PSP-based $\mathrm{K}^{+}$-type PD sensor was characterised by a higher sensitivity in solutions of the strong electrolytes LysHCl, ThiaminCl, PyridoxinHCl, NovHCl, $\mathrm{KCl}, \mathrm{NaCl}$, and $\mathrm{MgSO}_{4}$ compared to the sensitivity of Niacin $(23 \pm 2 \mathrm{mV} / \mathrm{pC})$, which is a weak electrolyte (Figure 4$)$.

In PSP-based $\mathrm{H}^{+}$-type $\mathrm{PD}$ sensors, hydronium ions contributed to the Donnan potential. The hydronium ions competed with large organic cations during formation of the Donnan potential at the PSP/test solution interface because organic cations have hydrophilic and hydrophobic groups. 
TABLE 1: The factors for the estimation of the cross-sensitivity of sensors $A_{k}, B_{k}$.

\begin{tabular}{lcccccccccccc}
\hline $\begin{array}{l}\text { Determining } \\
\text { components }\end{array}$ & \multicolumn{3}{c}{ LysHCl, $\mathrm{KCl}, \mathrm{NaCl}, \mathrm{MgSO}_{4}$} & \multicolumn{3}{c}{ ThiaminCl, KCl, NaCl } & \multicolumn{3}{c}{ NovHCl, KCl, NaCl } & \multicolumn{2}{c}{ Niacin, PyridoxinHCl } \\
Sensor & $\mathrm{A}_{1}$ & $\mathrm{~B}_{1}$ & $\mathrm{~B}_{2}$ & $\mathrm{~B}_{3}$ & $\mathrm{~A}_{1}$ & $\mathrm{~B}_{1}$ & $\mathrm{~B}_{2}$ & $\mathrm{~A}_{1}$ & $\mathrm{~B}_{1}$ & $\mathrm{~B}_{2}$ & $\mathrm{~A}_{1}$ & $\mathrm{~A}_{2}$ \\
\hline $\begin{array}{l}S=(1 / n) \sum_{k=1}^{n} S_{k}, \\
\mathrm{mV} / \mathrm{pC}\end{array}$ & 40 & 27 & 29 & 13 & 41 & 28 & 44 & 46 & 34 & 42 & 29 & 33 \\
$K=1 / n \sum_{k=1}^{n} S_{k} / D_{k}$ & 9 & 5 & 6 & 3 & 5 & 7.5 & 11 & 15 & 4 & 2 & 8 & 16 \\
$F=S / D$ & 1.4 & 0.08 & 0.05 & 0.09 & 2 & 0.1 & 0.2 & 2 & 0.1 & 0.2 & 0.3 & 17 \\
\hline
\end{tabular}

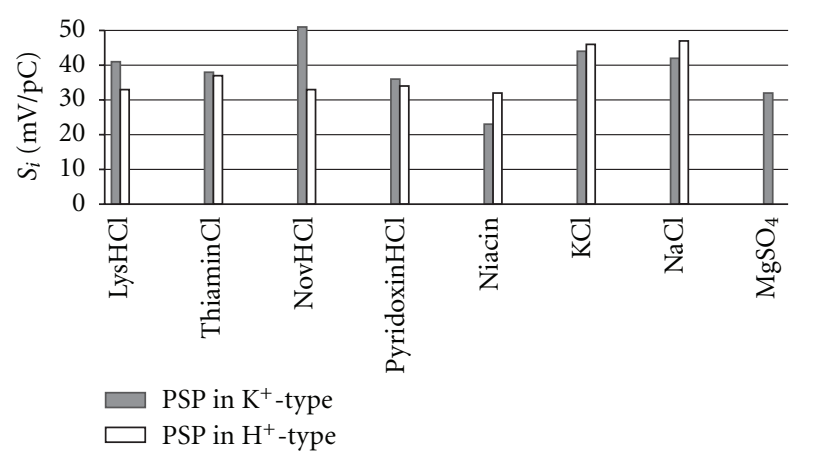

FIgURE 4: Sensitivity of PSP-based K-type (a) and $\mathrm{H}^{+}$-type (b) $\mathrm{PD}$ sensors in test solutions of $\mathrm{LysHCl}$, ThiaminCl, NovHCl, PyridoxinHCl, Niacin, $\mathrm{NaCl}, \mathrm{KCl}$, and $\mathrm{MgSO}_{4}$.

Additionally, the singly charged organic cations $\mathrm{LysH}^{+}$, Thiamin $\mathrm{H}^{+}$, and $\mathrm{NovH}^{+}$did not participate in ion-exchange reactions. These cations transformed into doubly-charged ions in the polymer phase as a result of a heterogeneous proteolytic reaction. Thus, adsorption at the interface of large doubly charged ions resulted in the decreased contribution of an organic component to the Donnan potential. As a result, the stability of the analytical signal of the PD sensor in such systems decreased. In some cases, the sensitivity to an organic component also decreased (e.g., by 1.2- and 1.5times to $\mathrm{LysH}^{+}$and $\mathrm{NovH}^{+}$, resp.). However, the sensitivity of PSP-based $\mathrm{H}^{+}$-type PD sensors to inorganic ions changed only slightly in comparison with PSP in salt forms (Figure 4).
The sensitivity of the PSP-based $\mathrm{H}^{+}$-type PD sensors to nicotinic acid increased by 1.5-times compared to PSP-based $\mathrm{K}^{+}$-type PD sensors (Figure 4). In the PSP-based $\mathrm{H}^{+}$-type $\mathrm{PD}$ sensors, both cations $\left(\mathrm{NiacinH}^{+}\right)$and zwitterions $\left(\mathrm{Niacin}^{ \pm}\right)$ of nicotinic acid contributed to the Donnan potential. Proteolytic reactions were the cause of Niacin ${ }^{ \pm}$ion contributions, which resulted in the transfer of cations to the PSP phase.

Thus, the use of PSPs in various ionic forms led to different PD sensor sensitivities toward the same organic component. However, the sensitivity of PD sensors toward inorganic ions changed insignificantly. The various influences of ionic forms of PSPs on the sensitivity to vitamins PyridoxinHCl and Niacin permitted the use of PD sensors for their joint determination in mixed aqueous solutions.

3.1. Multisensory Systems for Determination of Amino Acids, Vitamins, and Medical Substances. The potentiometric multisensory systems were developed for a multicomponent quantitative analysis of lysine monohydrochloride, thiamine chloride, and novocaine hydrochloride solutions that also contained chlorides of potassium and sodium. Additionally, solutions of nicotinic acid and pyridoxine hydrochloride were also analysed.

The sensor array for the analysis of solutions $\mathrm{LysHCl}+$ $\mathrm{KCl}+\mathrm{NaCl}$, ThiaminCl $+\mathrm{KCl}+\mathrm{NaCl}$, and $\mathrm{NovHCl}+\mathrm{KCl}+$ $\mathrm{NaCl}$ included the PSP-based $\mathrm{K}^{+}$-type PD sensor $\left(\mathrm{A}_{1}\right), \mathrm{K}$ $\mathrm{SE}\left(\mathrm{B}_{1}\right)$, Na-SE $\left(\mathrm{B}_{2}\right)$, and silver chloride/silver reference electrode $(\mathrm{C})$. The electrochemical circuits for the determination of the responses of the sensor array are described by

(A1) $\mathrm{Ag}|\mathrm{AgCl}, 1 \mathrm{M} \mathrm{KCl}| \mathrm{K}^{+}$-type PSP | test solution | sat. $\mathrm{KCl}, \mathrm{AgCl} \mid \mathrm{Ag}, \quad(\mathrm{C})$,

(B1) Ag | AgCl, 0.1 M KCl | PVC membrane | test solution | sat. KCl, AgCl | Ag, (C),

(B2) $\mathrm{Ag}|\mathrm{AgCl}, 0.1 \mathrm{M} \mathrm{HCl}|$ glass membrane | test solution | sat. $\mathrm{KCl}, \mathrm{AgCl} \mid \mathrm{Ag}, \quad(\mathrm{C})$.

The sensor array for the analysis of solutions $\mathrm{LysHCl}+$ $\mathrm{KCl}+\mathrm{NaCl}+\mathrm{MgSO}_{4}$ included $\mathrm{Mg}(\mathrm{Ca})-\mathrm{SE}\left(\mathrm{B}_{3}\right)$ and sensors $A_{1}, B_{1}, B_{2}$, and $C$. The electrochemical circuits for the determination of the response of the sensor array are described by (5)-(8): 
According to reference [24], a cross-sensitive sensor must be characterised by a sensitivity factor $S>25 \mathrm{mV} / \mathrm{pC}$, a stability factor $K>2$, and a nonselectivity factor $F>0.5$. Shown in Table 1 are the values of the factors $S, K$, and $F$ to ions $\mathrm{LysH}^{+}, \mathrm{K}^{+}, \mathrm{Na}^{+}, \mathrm{Mg}^{2+}$; Thiamin ${ }^{+}, \mathrm{K}^{+}$, and $\mathrm{Na}^{+}$, and $\mathrm{NovH}^{+}, \mathrm{K}^{+}$, and $\mathrm{Na}^{+}$for sensors $\mathrm{A}_{1}$ and $\mathrm{B}_{k}$, respectively. The values of factors $S, K$, and $F$ were calculated on the basis of experimental data (Figure 4) that were obtained by sensor calibrations in test solutions $\left(S_{i}(\mathrm{mV} / \mathrm{pC})=\right.$ individual angle coefficient, $D_{i}(\mathrm{mV} / \mathrm{pC})^{2}=$ dispersion of individual angle coefficient, and $D(\mathrm{mV} / \mathrm{pC})^{2}=$ dispersion of average angle).

Large sensitivity and nonselectivity factors for the PSPbased $\mathrm{K}^{+}$-type $\mathrm{PD}$ sensor in the groups of ions (Table 1) predicted commensurable contributions of corresponding ions to the $\mathrm{PD}$ sensor response in $\mathrm{LysHCl}+\mathrm{KCl}+\mathrm{NaCl}$,
ThiaminCl $+\mathrm{KCl}+\mathrm{NaCl}$ and $\mathrm{NovHCl}+\mathrm{KCl}+\mathrm{NaCl}$ solutions.

ISEs were not as highly selective in test solutions. For example, $\mathrm{Mg}(\mathrm{Ca})-\mathrm{SE}$ had an average angle lower than $25 \mathrm{mV} / \mathrm{pC}$ (Table 1). The preferential sensitivity of ISEs to corresponding inorganic ions caused low nonselectivity factors. However, the main requirement for ISE selection is response stability $(>2)$ toward defined components when cross-sensitive PD sensors are present in a sensor array.

The sensor array for the analysis of Pyridoxin $\mathrm{HCl}+$ Niacin solutions included two PSP-based $\mathrm{K}^{+}-\left(\mathrm{A}_{1}\right)$ and $\mathrm{H}^{+}$type $\left(\mathrm{A}_{2}\right)$ PD sensors and a reference electrode $(\mathrm{C})$. The electrochemical circuit for the determination of PD sensor responses is described by (5) and (9)

(A2) $\mathrm{Ag}|\mathrm{AgCl}, 1 \mathrm{M} \mathrm{HCl}| \mathrm{H}^{+}$-type PSP | test solution | sat. $\mathrm{KCl}, \mathrm{AgCl} \mid \mathrm{Ag}$.

Shown in Table 1 are the values of the cross-sensitivity criteria for PD sensors in individual solutions of PyridoxinHCl and Niacin. Significant values of factors $S, F$, and $K$ permitted the use of PSP-based $\mathrm{K}^{+}$- and $\mathrm{H}^{+}$-type $\mathrm{PD}$ sensors for the determination of Pyridoxin $\mathrm{HCl}$ and Niacin in their mixed aqueous solutions. Thus, the various sensitivities of the sensors to defined components (Figure 4) predicted a significant distinction of their contributions to sensor responses in the mixed solutions.

The mixed test solutions LysHCl $+\mathrm{KCl}+\mathrm{NaCl}$, Thi$\operatorname{aminCl}+\mathrm{KCl}+\mathrm{NaCl}, \mathrm{NovHCl}+\mathrm{KCl}+\mathrm{NaCl}$, and PyridoxinHCl + Niacin were studied for the multivariate calibration of the sensor array. All possible combinations of factors $\mathrm{pC}$ were examined for each analyte in the range of 24 with a constant step of $\mathrm{pC}=1$. The coefficient estimates from the multivariate calibration equations without taking into account any interference of components to the responses of sensors $\mathrm{A}_{k}$ and $\mathrm{B}_{k}$ are presented in Table 2 .

The coefficient estimates of the multivariate calibration equations, taking into account the interference of components on the responses of sensors $\mathrm{A}_{k}$ and $\mathrm{B}_{k}$, are presented in Table 3.

The equations were adequate at a confidence level of 0.05. The statistical models that took into account the interactions of factors reduced the errors of PD sensors and the errors of Na-SE by 1.3-2.3-times and 1.4-3.2-times, respectively, compared to statistical models that did not take into account the interactions of factors. The errors for $\mathrm{K}$ $\mathrm{SE}$ and $\mathrm{Mg}(\mathrm{Ca})-\mathrm{SE}$ did not change. Therefore, to calculate analyte concentrations, we used (4) for the PD sensor and $\mathrm{Na}-\mathrm{SE}$ and (3) for the K-SE and $\mathrm{Mg}(\mathrm{Ca})-\mathrm{SE}$.

Shown in Tables 4 and 5 are the actual and measured values of the analyte concentrations for some test solutions.

The number of replicate measurements was 6-8. The statistical data interpretation was made using a confidence coefficient of 0.95 . The relative error of measurement was $2-$ $10 \%$.
3.2. Determination of Lysine Monohydrochlorides and Novocaine Hydrochlorides in Therapeutic Products and Sewage from a Dental Clinic. The potentiometric multisensory system used to analyse $\mathrm{LysHCl}+\mathrm{KCl}+\mathrm{NaCl}+\mathrm{MgSO}_{4}$ solutions was used for the analysis of therapeutic "mineral salt with low content of sodium chloride" samples. This product contained $\mathrm{NaCl}, \mathrm{KCl}, \mathrm{MgSO}_{4}$, and $\mathrm{LysHCl}$ in the following mass rations (\%): $0.35-0.58 ; 0.31-0.40 ; 0.05-0.10$ and $0.02-$ 0.10 [40]. The responses of sensors $A_{1}, B_{1}, B_{2}$, and $B_{3}$ were measured against a reference electrode $C$ in aqueous solutions of $1 \mathrm{~g} / \mathrm{l}$ of salt. The defined concentrations of $\mathrm{LysH}$, $\mathrm{K}^{+}, \mathrm{Na}^{+}$, and $\mathrm{Mg}^{2+}$ were $1.0 \cdot 10^{-4} \pm 0.4 \cdot 10^{-4} \mathrm{M}(0.054 \pm$ $0.004 \% \mathrm{LysHCl}$ in dry sample), $5.1 \cdot 10^{-3} \pm 0.3 \cdot 10^{-3} \mathrm{M}(0.38 \pm$ $0.02 \% \mathrm{KCl}$ in dry sample), $9.0 \cdot 10^{-3} \pm 0.5 \cdot 10^{-3} \mathrm{M}(0.02 \pm$ $0.008 \% \mathrm{NaCl}$ in dry sample), and $4.5 \cdot 10^{-4} \pm 0.3 \cdot 10^{-4} \mathrm{M}$ $\left(0.53 \pm 0.04 \% \mathrm{MgSO}_{4}\right.$ in dry sample $)$, respectively. Thus, the measured composition of the therapeutic salt samples was in agreement with the stated product composition.

The potentiometric multisensory system used to analyse $\mathrm{NovHCl}+\mathrm{KCl}+\mathrm{NaCl}$ solutions was used to analyse sewage samples from a dental clinic. The responses of sensors $A_{1}$, $B_{1}$, and $B_{2}$ were measured against reference electrode $C$ in sewage samples. These samples were taken from a sewer knee before and after a patient's reception. The disparity of $\mathrm{NovH}^{+}$concentrations in the dental clinic sewage before and after the patient's reception was $(0.44 \pm 0.01) \cdot 10^{-5} \mathrm{M}$. The concentrations of $\mathrm{K}^{+}$and $\mathrm{Na}^{+}$in the sewage were $2.1 \cdot 10^{-3} \mathrm{M}$ and $1.7 \cdot 10^{-2} \mathrm{M}$, respectively, that is, in concordance with [41]. Regular drainage of novocaine hydrochloride into the sewage is a serious problem because the medications are toxic substances with narcotic activity.

\section{Conclusion}

Here, the development of potentiometric multisensory systems, in which novel potentiometric PD sensors were crosssensitive was described. The analytical signal of PD sensors 


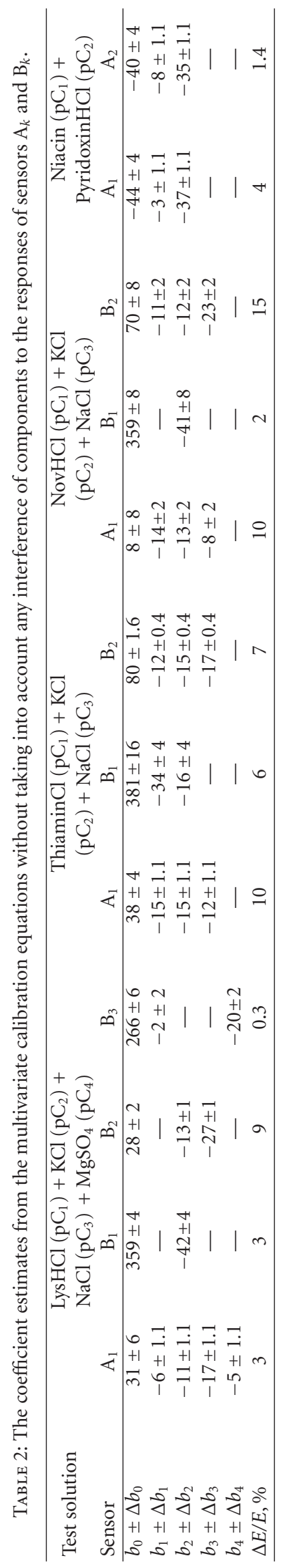




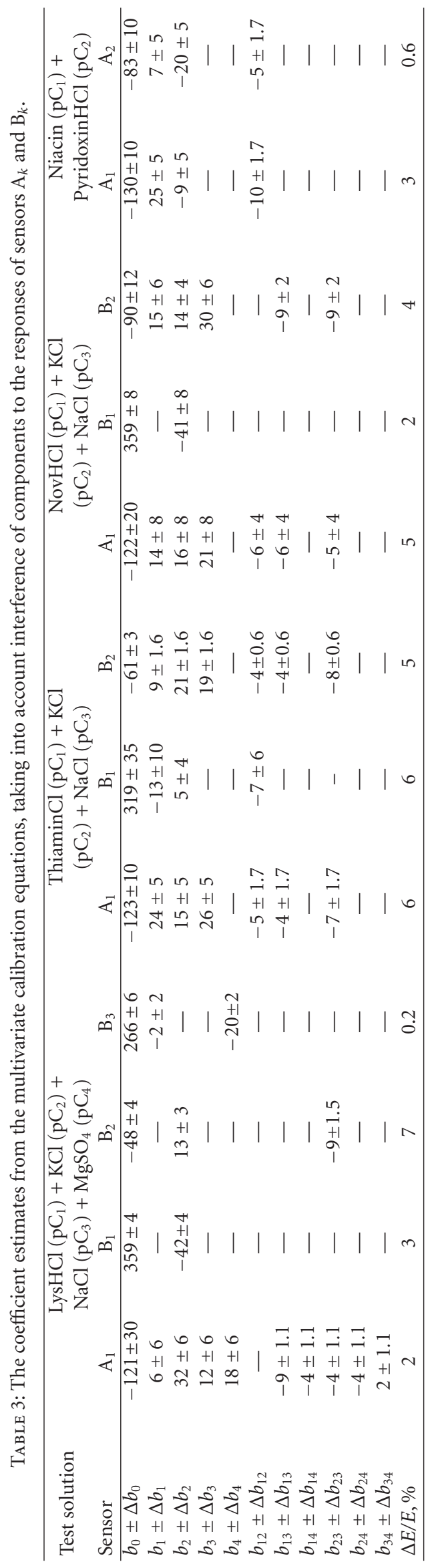


TABLE 4: The actual and measured values of the analyte concentrations for some test solutions ThiaminCl $+\mathrm{KCl}+\mathrm{NaCl}$, $\mathrm{NovHCl}+\mathrm{KCl}+$ $\mathrm{NaCl}$.

\begin{tabular}{|c|c|c|c|c|c|c|}
\hline \multirow{2}{*}{ Test solution } & \multicolumn{3}{|c|}{ Added, M } & \multicolumn{3}{|c|}{ Found, $\mathrm{M}$} \\
\hline & $\mathrm{X}^{+}$ & $\mathrm{K}^{+}$ & $\mathrm{Na}^{+}$ & $\mathrm{X}^{+}$ & $\mathrm{K}^{+}$ & $\mathrm{Na}^{+}$ \\
\hline \multirow{3}{*}{$\begin{array}{l}\operatorname{Thiamin}^{+} \\
\text {ThiaminH } \\
\mathrm{Na}^{+} \mathrm{Cl}^{-}\end{array}$} & $1.0 \cdot 10^{-4}$ & $1.0 \cdot 10^{-3}$ & $1.0 \cdot 10^{-2}$ & $(1.0+0.05) \cdot 10^{-4}$ & $(1.0+0.10) \cdot 10^{-3}$ & $(1.0+0.12) \cdot 10^{-2}$ \\
\hline & $1.0 \cdot 10^{-3}$ & $1.0 \cdot 10^{-2}$ & $1.0 \cdot 10^{-3}$ & $(1.0 \pm 0.04) \cdot 10^{-3}$ & $(1.0 \pm 0.13) \cdot 10^{-2}$ & $(1.0 \pm 0.04) \cdot 10^{-3}$ \\
\hline & $1.0 \cdot 10^{-2}$ & $1.0 \cdot 10^{-4}$ & $1.0 \cdot 10^{-3}$ & $(1.0 \pm 0.03) \cdot 10^{-2}$ & $(1.0 \pm 0.15) \cdot 10^{-4}$ & $(1.0 \pm 0.04) \cdot 10^{-3}$ \\
\hline \multirow{3}{*}{$\begin{array}{l}\mathrm{NovH}^{+}(\mathrm{X}) \mathrm{K}^{+} \\
\mathrm{Na}^{+} \mathrm{Cl}^{-}\end{array}$} & $1.0 \cdot 10^{-4}$ & $1.0 \cdot 10^{-4}$ & $1.0 \cdot 10^{-4}$ & $(1.0 \pm 0.03) \cdot 10^{-4}$ & $(1.0 \pm 0.10) \cdot 10^{-4}$ & $(1.0 \pm 0.20) \cdot 10^{-4}$ \\
\hline & $1.0 \cdot 10^{-4}$ & $1.0 \cdot 10^{-3}$ & $1.0 \cdot 10^{-2}$ & $(1.0 \pm 0.02) \cdot 10^{-4}$ & $(1.0 \pm 0.11) \cdot 10^{-3}$ & $(1.1 \pm 0.10) \cdot 10^{-2}$ \\
\hline & $1.0 \cdot 10^{-3}$ & $1.0 \cdot 10^{-2}$ & $1.0 \cdot 10^{-3}$ & $(1.0 \pm 0.01) \cdot 10^{-3}$ & $(1.1 \pm 0.01) \cdot 10^{-2}$ & $(1.0 \pm 0.02) \cdot 10^{-3}$ \\
\hline
\end{tabular}

TABLe 5: The actual and measured values of the analyte concentrations for some test solutions Pyridoxin $\mathrm{HCl}+\mathrm{Niacin}$.

\begin{tabular}{|c|c|c|c|c|}
\hline \multirow{2}{*}{ Test solution } & \multicolumn{2}{|c|}{ Added, $\mathrm{M}$} & \multicolumn{2}{|c|}{ Found, $\mathrm{M}$} \\
\hline & Pyridoxin $^{+}$ & Niacin & Pyridoxin $^{+}$ & Niacin \\
\hline Pyridoxin $^{+}$ & $1.0 \cdot 10^{-4}$ & $1.0 \cdot 10^{-2}$ & $(1.0 \pm 0.012) \cdot 10^{-4}$ & $(1.0 \pm 0.015) \cdot 10^{-2}$ \\
\hline Niacin $^{+}$ & $1.0 \cdot 10^{-3}$ & $1.0 \cdot 10^{-3}$ & $(1.1 \pm 0.012) \cdot 10^{-3}$ & $(1.0 \pm 0.015) \cdot 10^{-3}$ \\
\hline $\mathrm{Niacin}^{ \pm} \mathrm{Cl}^{-}$ & $1.0 \cdot 10^{-2}$ & $1.0 \cdot 10^{-4}$ & $(1.0 \pm 0.012) \cdot 10^{-2}$ & $(1.0 \pm 0.015) \cdot 10^{-4}$ \\
\hline
\end{tabular}

is the Donnan potential at the individual PSP/test electrolyte solution interface. The use of the membrane potential equilibrium component as an analytical signal, which is the Donnan potential at the IEP/test solution interface, resulted in the elimination of migration and diffusion problems inherent in potentiometric sensors. As a result, the accuracy and stability of the analysis subsequently increased. The use of novel sensors for the quantitative analysis of multicomponent aqueous solutions of amino acids, vitamins, and medical substances was based on proteolytic and ion-exchange reactions at the PSP/test solution interface. The potentiometric sensor arrays were developed for multicomponent quantitative analyses of lysine monohydrochloride, thiamine chloride, and novocaine hydrochloride solutions containing salts of alkaline and alkaline-earth metals as well as mixed solutions of nicotinic acid and pyridoxine hydrochloride. The sensor arrays consisted of cross-sensitive PD sensors and ISEs. The multivariate methods of the analysis were used for sensor calibrations in addition to the analysis of the total response of the sensor arrays. The relative errors of electrolyte measurements in aqueous solutions did not exceed $10 \%$.

The developed multisensory systems were then used to determine the composition of therapeutic "mineral salt with low content of sodium chloride" and dental clinic sewage.

The PD sensor multisensory systems made it possible to perform quantitative analyses of multicomponent solutions of different electrolytes, which is in contrast to the majority of known potentiometric sensors arrays that only permit semiquantitative analyses.

\section{Acknowledgments}

The authors thank cand.ch.sc., the chief of the laboratory of Membrane Processes OSS "Plastpolymer" (St. Petersburg, Russia) Timofeev Sergey Vasilevich for giving samples of perfluorinated sulphonic cation-exchange membranes, tubes, and rods. This study was funded by the Russian Fund of Fundamental Research (09-03-97505 r_center_a).

\section{References}

[1] D. Özdemir and E. Dinc, "Determination of thiamine $\mathrm{HCl}$ and pyridoxine $\mathrm{HCl}$ in pharmaceutical preparations using UVVisible spectrophotometry and genetic algorithm based multivariate calibration methods," Chemical and Pharmaceutical Bulletin, vol. 52, no. 7, pp. 810-817, 2004.

[2] F. Feng, K. Wang, Z. Chen, Q. Chen, J. Lin, and S. Huang, "Flow injection renewable drops spectrofluorimetry for sequential determinations of Vitamins B1, B2 and B6," Analytica Chimica Acta, vol. 527, no. 2, pp. 187-193, 2004.

[3] Z. Chen, B. Chen, and S. Yao, "High-performance liquid chromatography/electrospray ionization-mass spectrometry for simultaneous determination of taurine and 10 watersoluble vitamins in multivitamin tablets," Analytica Chimica Acta, vol. 569, no. 1-2, pp. 169-175, 2006.

[4] A. Scholz, Ed., Electrochemical Methods: Guide to Experiments and Applications, Springer, Berlin, Germany, 2010.

[5] P. Gründler, Chemical Sensors: An Introduction for Scientists and Engineers, Springer, Berlin, Germany, 2006.

[6] J. Bobacka, A. Ivaska, and A. Lewenstam, "Potentiometric ion sensors," Chemical Reviews, vol. 108, no. 2, pp. 329-351, 2008.

[7] B. P. Nikolsky, M. M. Shultz, A. A. Belijustin, and A. A. Lev, Glass Electrodes for Hydrogen and Other Cations, E-Publishing, New York, NY, USA, 1967, Edited by G. Eisenman.

[8] Z. Boksay and B. Lengyuel, "Vacancy type mechanism of the electrical relaxation processes in glass," Journal of NonCrystalline Solids, vol. 14, no. 1, pp. 79-87, 1974.

[9] G. Eisenman, D. O. Rudin, and J. U. Casby, "Glass electrode for measuring sodium ion," Science, vol. 126 , no. 3278, pp. 831834, 1957.

[10] A. A. Belyustin, "The centenary of glass electrode: from Max Cremer to F. G. K. Baucke," Journal of Solid State Electrochemistry, vol. 15, no. 1, pp. 47-65, 2011.

[11] R. -Q. Yu, Z. -R. Zhang, and G. -L. Shen, "Potentiometric sensors: aspects of the recent development," Sensors and Actuators $B$, vol. 65, no. 1, pp. 150-153, 2000. 
[12] A. R. Pires, A. N. Araújo, M. C. B. S. M. Montenegro, P. Chocholous, and P. Solich, "New ionophores for vitamin B1 and vitamin B6 potentiometric sensors for multivitaminic control," Journal of Pharmaceutical and Biomedical Analysis, vol. 46, no. 4, pp. 683-691, 2008.

[13] E. Bakker and M. E. Meyerhoff, "Ionophore-based membrane electrodes: new analytical concepts and non-classical response mechanisms," Analytica Chimica Acta, vol. 416, no. 2, pp. 121$137,2000$.

[14] P. Ciosek, R. Mamińska, A. Dybko, and W. Wróblewski, "Potentiometric electronic tongue based on integrated array of microelectrodes," Sensors and Actuators B, vol. 127, no. 1, pp. 8-14, 2007.

[15] E. Bakker and E. Pretsch, "Nanoscale potentiometry," Trends in Analytical Chemistry, vol. 27, no. 7, pp. 612-618, 2008.

[16] E. Bakker, "Determination of unbiased selectivity coefficients of neutral carrier-based cation-selective electrodes," Analytical Chemistry, vol. 69, no. 6, pp. 1061-1069, 1997.

[17] A. Ceresa, A. Radu, S. Peper, E. Bakker, and E. Pretsch, "Rational design of potentiometric trace level ion sensors. A Ag+selective electrode with a 100 ppt detection limit," Analytical Chemistry, vol. 74, no. 16, pp. 4027-4036, 2002.

[18] J. Janata and M. Josowicz, "Nernstian and non-nernstian potentiometry," Solid State Ionics, vol. 94, no. 1-4, pp. 209-215, 1997.

[19] A. Mimendia, J. M. Gutiérrez, L. Leija et al., "A review of the use of the potentiometric electronic tongue in the monitoring of environmental systems," Environmental Modelling and Software, vol. 25, no. 9, pp. 1023-1030, 2010.

[20] L. Escuder-Gilabert and M. Peris, "Review: highlights in recent applications of electronic tongues in food analysis," Analytica Chimica Acta, vol. 665, no. 1, pp. 15-25, 2010.

[21] A. V. Legin, A. M. Rudnitskaya, Y. G. Vlasov, C. Di Natale, and A. D'Amico, "Features of the electronic tongue in comparison with the characteristics of the discrete ion-selective sensors," Sensors and Actuators B, vol. 58, no. 1-3, pp. 464-468, 1999.

[22] A. V. Legin, E. A. Bychkov, and Y. G. Vlasov, "Analytical applications of chalcogenide glass chemical sensors in environmental monitoring and process control," Sensors and Actuators B, vol. 24, no. 1-3, pp. 309-311, 1995.

[23] A. V. Legin, E. A. Bychkov, and Y. G. Vlasov, "Analytical applications of chalcogenide glass chemical sensors in environmental monitoring and process control," Sensors and Actuators B, vol. 24, no. 1-3, pp. 309-311, 1995.

[24] A. Rudnitskaya, A. Ehlert, A. Legin, Y. Vlasov, and S. Büttgenbach, "Multisensor system on the basis of an array of nonspecific chemical sensors and artificial neural networks for determination of inorganic pollutants in a model groundwater," Talanta, vol. 55, no. 2, pp. 425-431, 2001.

[25] A. V. Legin, D. O. Kirsanov, V. A. Babain, A. V. Borovoy, and R. S. Herbst, "Cross-sensitive rare-earth metal sensors based on bidentate neutral organophosphorus compounds and chlorinated cobalt dicarbollide," Analytica Chimica Acta, vol. 572, no. 2, pp. 243-247, 2006.

[26] N. Garsia-Villar, J. Saurina, and S. Hernandez-Cassou, "Potentiometric sensor array for the determination of lysine in feed samples using multivariate calibration methods," Fresenius' Journal of Analytical Chemistry, vol. 371, pp. 1001-1008, 2001.

[27] B. K. Lavine and J. Workman, "Chemometrics," Analytical Chemistry, vol. 74, no. 12, pp. 2763-2769, 2002.

[28] O. V. Bobreshova, M. V. Agupova, and A. V. Parshina, "Potentiometric determination of lysine in aqueous solutions using MF-4SK modified perfluorinated membranes," Journal of Analytical Chemistry, vol. 64, no. 6, pp. 642-647, 2009.
[29] O. V. Bobreshova, A. V. Parshina, and E. A. Ryzhkova, "Determination of the ionic composition of perfluorinated sulfocationite membranes based on Donnan potential estimates," Russian Journal of Electrochemistry, vol. 45, no. 11, pp. 12341239, 2009.

[30] O. V. Bobreshova, A. V. Parshina, M. V. Agupova, and K. A. Polumestnaya, "Determination of amino acids, vitamins, and drug substances in aqueous solutions using new potentiometric sensors with Donnan potential as analytical signal," Russian Journal of Electrochemistry, vol. 46, no. 11, pp. 1252-1262, 2010.

[31] O. V. Bobreshova, A. V. Parshina, and K. A. Polumestnaya, "A new type of potentiometric sensors based on perfluorinated, sulfonated cation exchange membranes for quantitative analysis of multicomponent aqueous solutions," Petroleum Chemistry, vol. 51, pp. 492-501, 2011.

[32] O. V. Bobreshova, M. V. Agupova, A. V. Parshina, and S. V. Timofeev, RF patent no. 2376591, 2009, Byull. izobret., no. 35, $6 \mathrm{p}, 2009$.

[33] O. V. Bobreshova, A. V. Parshina, S. V. Timofeev, and K. A. Polumestnaya, RF patent no. 87260, 2009, Byull. izobret., no. 27, 2 p, 2009.

[34] F. G. Donnan, "Theory of membrane equilibria and membrane potentials in the presence of non-dialysing electrolytes. A contribution to physical-chemical physiology," Journal of Membrane Science, vol. 100, no. 1, pp. 45-55, 1995.

[35] R. L. Gustafson, "Donnan Equilibria in Polystyrenesulfonate Gels," The Journal of Physical Chemistry, vol. 70, pp. 957-961, 1966.

[36] R. P. Back and P. Vanysek, "Interfacial potential differences at mixed conductor interfaces: Nernst, Nernst-Donnan, Nernst Distribution and generalization," Journal of Electroanalytical Chemistry, vol. 292, pp. 73-91, 1990.

[37] F. Helfferich, "Ionenaustauscher," in Grundlagen Struktur-Herstellung-Theorie, vol. 1, Chemie, Weinheim, Germany, 1959.

[38] M. Higa, A. Tanioka, and A. Kira, "A novel measurement method of Donnan potential at an interface between a charged membrane and mixed salt solution," Journal of Membrane Science, vol. 140, no. 2, pp. 213-220, 1998.

[39] H. G. Haubold, T. Vad, H. Jungbluth, and P. Hiller, "Nano structure of NAFION: a SAXS study," Electrochimica Acta, vol. 46, no. 10-11, pp. 1559-1563, 2001.

[40] O. V. Bobreshova, P. I. Kulintsov, L. A. Zagorodnykh, and V. I. Popov, RF patent no. 2286071, 2004, Byull. izobret., no. 30, 2 p., 2006.

[41] E. Emmanuel, M. G. Pierre, and Y. Perrodin, "Groundwater contamination by microbiological and chemical substances released from hospital wastewater: health risk assessment for drinking water consumers," Environment International, vol. 35, no. 4, pp. 718-726, 2009. 


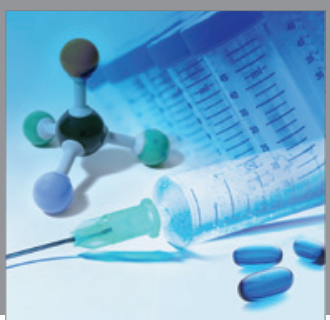

International Journal of

Medicinal Chemistry

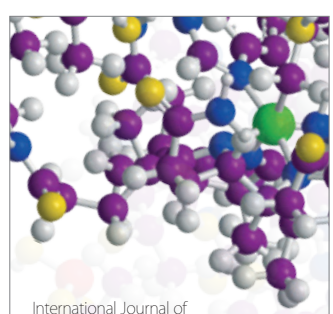

Carbohydrate Chemistry

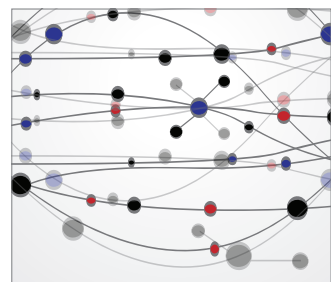

The Scientific World Journal
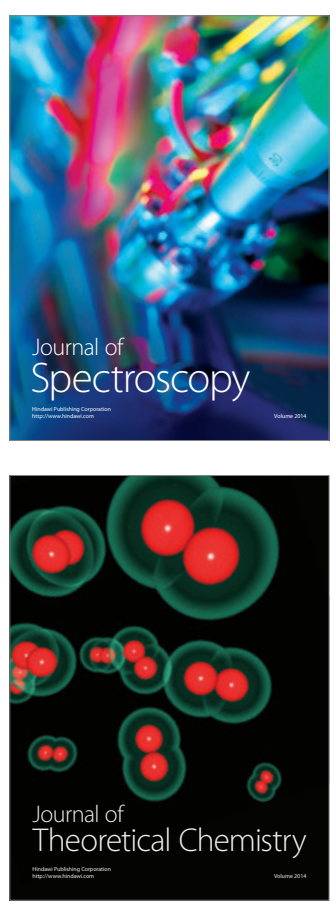
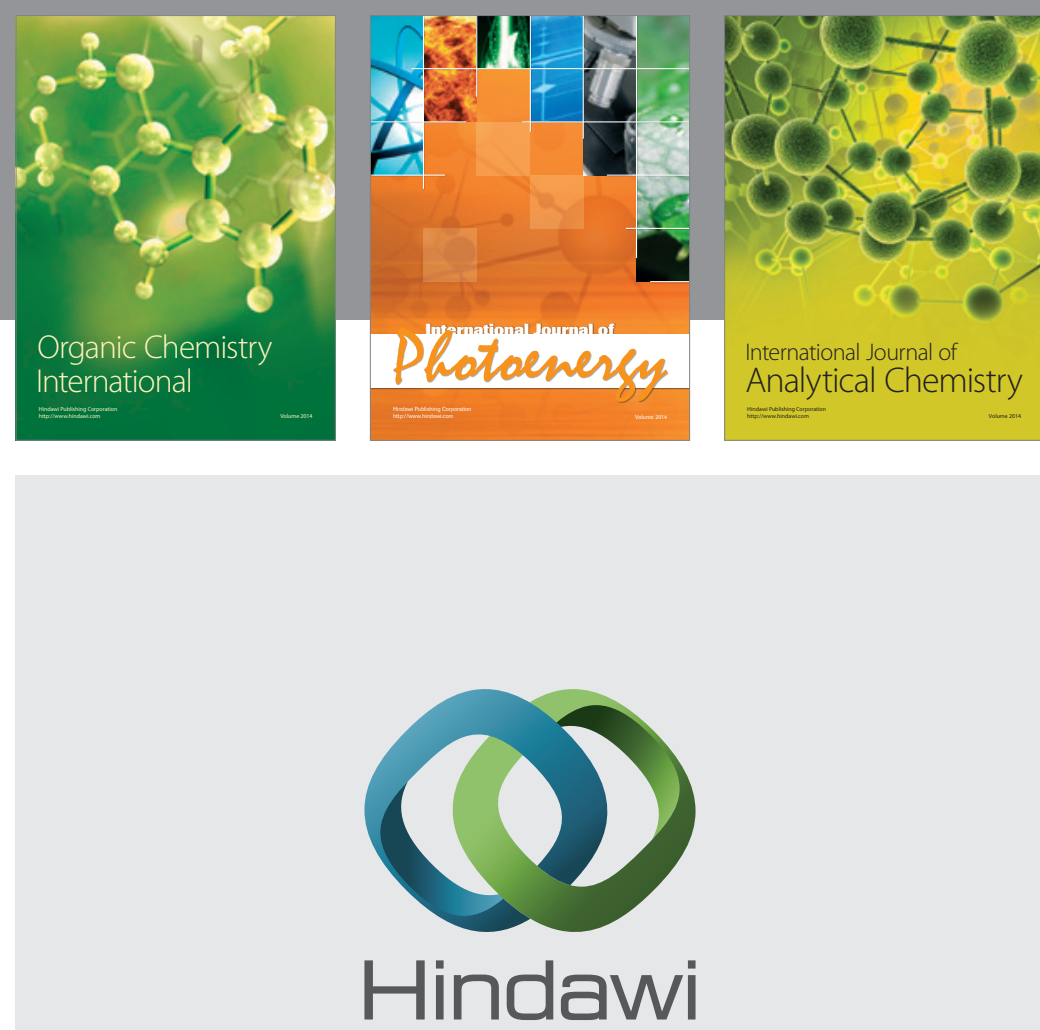

Submit your manuscripts at

http://www.hindawi.com
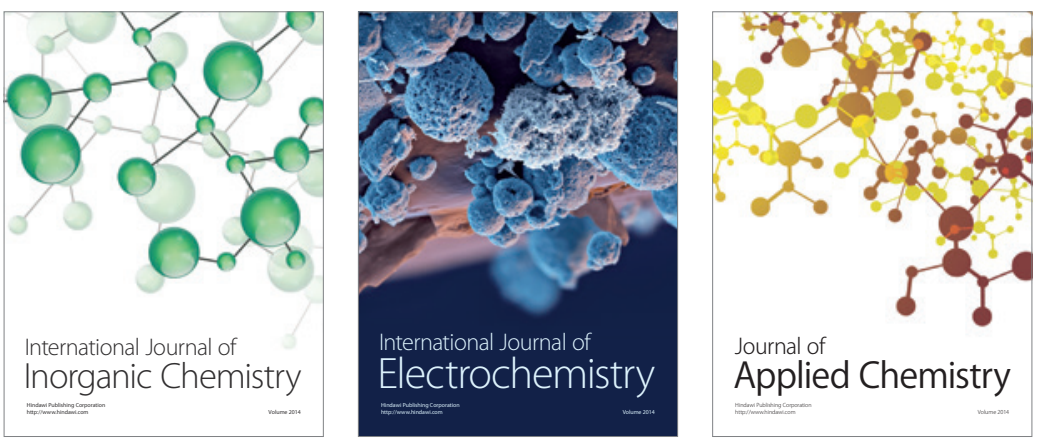

Journal of

Applied Chemistry
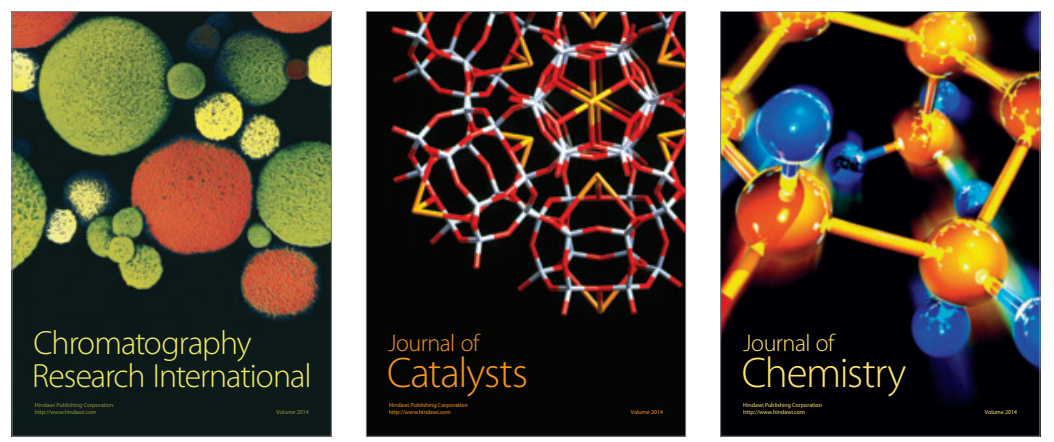
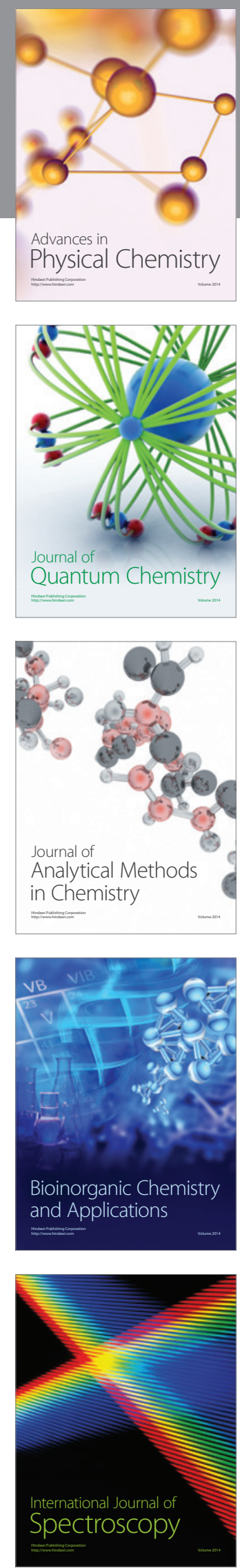